\title{
KEUNGGULAN BERSAING INDUSTRI KREATIF KRIYA
}

\author{
Mohammad Benny Alexandri ${ }^{1}$, Arianis Chan ${ }^{2}$ \\ Program Studi Magister Kebijakan Publik, Fakultas Ilmu Sosial dan Ilmu Politik \\ Universitas Padjadjaran \\ bennyalexandri@yahoo.co.id, arianis0429@yahoo.com
}

\begin{abstract}
ABSTRAK
Industri kreatif adalah pendorong utama penciptaan pekerjaan, inovasi, dan inklusi sosial. Industri kreatif juga memiliki pengaruh penting dalam kekayaan suatu daerah. Tulisan ini bertujuan untuk melihat perkembangan industri kreatif, khususnya sub sektor kerajinan dan keunggulan bersaingnya. Desa Boneka Sukamulya telah berdiri sejak tahun 1990-an. Sebagai pusat industri, seperti Binong Jati, ada beberapa perintis utama pendirian di pusat industri boneka. Desa Boneka Sukamulya dipelopori oleh Haji Atang, karena ketika industri lain menurun secara drastis bisnis boneka buatan memiliki prospek peningkatan yang stabil dan cenderung positif. Metode penelitian yang digunakan dalam makalah ini adalah metode systematic mapping study dan Analisis SWOT (Kekuatan, Kelemahan, Peluang, Ancaman). Tujuan dari penelitian ini adalah, 1. Bagaimana kondisi saat ini Industri Kampung Boneka Sukamulya, 2. Apakah masalah yang dihadapi Industri Kampung Boneka Sukamulya, 3. Apakah keunggulan bersaing yang dapat diterapkan Industri Kampung Boneka Sukamulya dalam menghadapi permasalahan yang ada.. Kesimpulan untuk Desa Boneka Sukamulya adalah memiliki potensi besar. Potensi ini dapat berkontribusi besar terhadap pertumbuhan ekonomi kreatif dan lapangan kerja. Desa Boneka Sukamulya masih memiliki kendala yang harus dihadapi yaitu bahan baku dan pesaing.
\end{abstract}

Keyword : Creative Industry, metode systematic mapping study, SWOT Analysis, Craft, Kampung Boneka (Doll Village), Sukamulya

\section{Pendahuluan}

Keunggulan kompetitif adalah keuntungan lebih dari pesaing yang diperoleh dengan menawarkan konsumen nilai yang lebih besar, baik dengan cara harga yang lebih rendah atau dengan memberikan manfaat yang lebih besar dan layanan yang membenarkan harga yang lebih tinggi, Porter (2001). Menurut Barney dan Clark (1991) dalam Resource-Based Theory: Creating and Sustaining Competitive Advantage, menyebutkan bahwa sumber keunggulan kompetitif meliputi sumber daya, orisinil, tidak dapat ditiru, dan tidak ada substitusinya. Sumber daya yang dimaksud meliputi semua aset, kapabilitas, proses organisasional, karakteristik perusahaan, informasi, pengetahuan dan sebagainya yang mana sumber daya ini berada dalam kendali perusahaan untuk implementasi strategi agar tercapai keefektifan dan efisiensi (Barney, 1986; 1988; 1991; 1996; 2001).

Oleh karena itu, untuk mendapatkan perspektif penelitian yang ada, peneliti melakukan studi pemetaan sistematis (systematic mapping study). Studi ini merupakan tinjauan literatur dengan menggunakan systematic mapping study (SMS) mengenai keunggulan kompetitif, meskipun ada beberapa tinjauan literatur terkait keunggulan kompetitif yang dilakukan di Indonesia (Handayani et al., 2013; Napitupulu et al., 2013; Susanti et al., 2015; Ginting, 2015; Roostika et al., 2015; Widodo, 2015; Tjahjaningsih et al., 2016; Rufaidah, 2016; Ismail, 2016; Sulistyo et al., 2016; Samsir et al., 2017; Budiarto et al., 2017; Mustofa et al., 2017; Lukiastuti et al., 2017; Ardyan et al., 2017), namun hanya sedikit yang membahas spesifik systematic mapping study (SMS) mengenai keunggulan kompetitif (Kahkonen \& Smolander, 2013). Maka, tujuan dari penelitian ini adalah menyediakan peta literatur yang ada untuk mencapai hasil yang bermanfaat bagi penggunaan praktis dan juga untuk bagi akademisi untuk mengidentifikasi kesenjangan penelitian (gaps) di masa yang akan datang (Akkermans, Bogerd, \& van Wassenhove, 2003).

Di Indonesia sendiri, kehadiran ekonomi kreatif berpotensi dalam memberikan kontribusi ekonomi yang signifikan, menciptakan iklim bisnis yang positif, membangun citra dan identitas bangsa, meningkatkan keunggulan kompetitif, dan 
memberikan dampak sosial yang positif (Laporan Penyusunan PDRB EKRAF 5 Provinsi 2010-2016 Menurut Lapangan Usaha,Badan Ekonomi Kreatif)

Pada tahun 2016, subsektor ekonomi kreatif yang mempunyai PDRB atas dasar harga berlaku tertinggi adalah subsektor Kuliner dengan nilai sebesar 236.011,25 miliar rupiah dan yang mempunyai besaran PDRB atas dasar terkecil adalah subsektor Desain Komunikasi Visual dengan nilai sebesar 82,54 miliar rupiah. Pada tahun 2016 terdapat tiga subsektor ekonomi kreatif yang mempunyai nominal PDRB atas dasar harga berlaku di atas 50.000 miliar rupiah, yaitu subsektor Kriya, subsektor Kuliner, dan subsektor Fesyen.

Setiap tahun di 5 provinsi, PDRB ekonomi kreatif atas dasar harga konstan mengalami ratarata pertumbuhan sebesar 5,96 persen dan rata-rata PDRB ekonomi kreatif menyumbang 9,52 persen terhadap pembentukan PDRB Provinsi atas dasar harga konstan.

Penelitian ini akan berfokus pada industri kreatif UKM khususnya sub-sektor kriya. Subsektor kriya yang akan diteliti adalah industri boneka. Kampung Boneka Sukamulya Bandung berdiri sejak tahun 1990-an. Pelopor utama dari terbentuknya sentra industri boneka Sukamulya dipelopori oleh Haji Atang. Tapi seiring berubahnya pasar global, menurut data, Sentra Industri Boneka Sukamulya selalu menurun dari tahun ke tahun. Jumlah unit usaha yang beroperasi tetap sama dengan jumlah 17 unit usaha. Pada awalnya, sekitar tahun 1990-an, Haji Atang menjadi pelopor usaha membuat boneka di kampung Sukamulya. Usahanya ini membuat tetangganya tertarik karena orderan selalu ada setiap saat. Di saat usaha yang lain sedang menurun, usaha boneka buatan tangan ini justru makin banyak pesanan. Warga ikut terlibat dalam usaha ini, sehingga Kampung Sukamulya menjadi sentra industri boneka kain buatan tangan. Sedangkan pada tahun ini boneka merchandise paling banyak peminatnya. (http://panduanwisata.id).

Penelitian ini melihat perkembangan industri Kampung Boneka Sukamulya hingga saat ini yang menyebabkan jumlah tenaga kerja maupun peminat dari boneka buatan tangan Sukamulya berubah.

Adapun rumusan masalah yang diangkat dalam penelitian ini adalah :

1. Bagaimana kondisi saat ini Industri Kampung Boneka Sukamulya,

2. Apakah masalah yang dihadapi Industri Kampung Boneka Sukamulya,

3. Apakah keunggulan bersaing yang dapat diterapkan Industri Kampung Boneka Sukamulya dalam menghadapi permasalahan yang ada.

\section{Tinjauan Pustaka}

Menurut UNCTAD (2010) dalam Booyens (2012), industri kreatif merupakan pendorong utama penciptaan lapangan kerja, inovasi, dan sosial penyertaan. Industri kreatif juga memiliki pengaruh penting dalam kekayaan suatu wilayah (Molina et al., 2012). Menurut UNESCO di Dong \& Haruna (2012), industri kreatif melalui budaya telah menjadi tonggak sejarah ekonomi berbasis pasca-industri modern.

Cravens (1999) menyebutkab bahwa sumber keunggulan bersaing itu adalah ketrampilan, sumber daya dan pengendalian yang superior. Keterampilan yang superior memungkinkan organisasi untuk memilih dan melaksanakan strategi yang akan membedakan organisasi dan persaingan. Keterampilan mencakup kemampuan teknis , manajerial dan operasonal. Elemen-elemen keunggulan bersaing menurut Cravens (1999) dapat dilihat pada gambar 2.1

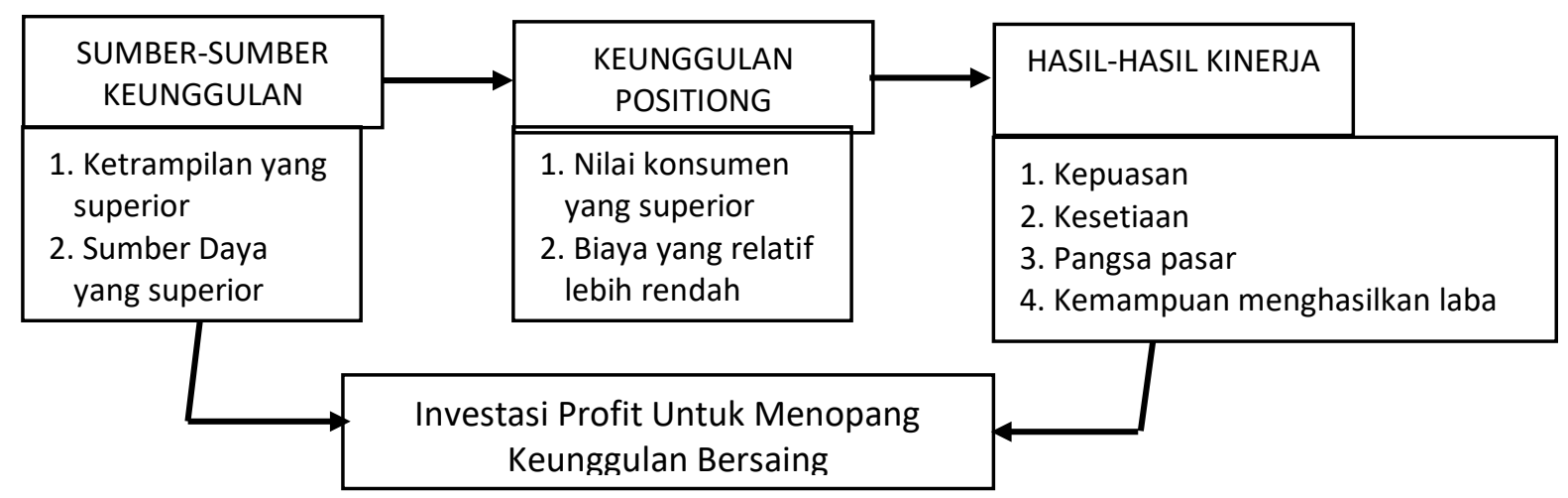

Gambar 2.1 Elemen-elemen Keunggulan Bersaing Sumber : Cravens (1999) 
Menurut Phil (2011:103) keunggulan bagi suatu organisasi adalah tentang membedakan dirinya dengan the Six P's, yaitu people (orang), policies (kebijakan), processes (proses), products (produk), practices (praktik) dan performance (kinerja). Menurut Phil, keunggulan harus dipandang secara terintegrasi dan interaktif, dengan pandangan terhadap perbaikan berkelanjutan, dan hasil akhir yang dicapai adalah keunggulan kinerja, dimana Phil berpendapat keunggulan kinerja hanya dapat diperoleh apabila mendapat dukungan dari semua komponen keunggulan lainnya.

Berdasarkan survey nasional dari Badan Ekonomi Kreatif (BEKRAF) pada PDB 2015, Industri Kreatif menyumbang sebesar 852,24 Triliun. Jumlah ini meningkat dari tahun sebelumnya sebesar 784,82 Triliun pada tahun 2014. Hal ini menunjukkan Industri Kreatif memiliki andil besar dalam peningkat pendapatkan negara. Berdasarkan data survey BEKRAF, Subsektor Kriya atau kerajinan menyumbang sebesar $15,70 \%$ dari Diskusi total sumbangan PDB dari Ekomoni Kreatif yaitu sebesar 852,4 Triliun pada tahun 2015. Kriya pun menjadi subsektor terbesar ketiga dalam penyumbang PDB Ekonomi Kreatif. Urutan pertama di raih oleh subsektor Kuliner sebanyak 41,69\%, disusul oleh Fashion sebesar 18,15\%. Ini menentukan bahwa Industri Kreatif sudah menjadi salah satu pemasok terbesar pada perekonomian Indonesia karena menyumbang lebih dari $7 \%$ Pendapatan Domestik Bruto.

\section{Metodologi}

Peneliti menerapkan metode systematic mapping study (Kitchenham, 2004; Petersen et al, 2008; Banaeianjahromi dan Smolander, 2016), untuk menentukan fokus apa yang telah dikaji dalam area penelitian ini.Penelitian ini juga menggunakan SWOT analisis untuk melihat keunggulan bersaing pada UMKM sektor industri kreatif di Kota Bandung.

1. Bagaimana kondisi saat ini Industri Kampung Boneka Sukamulya

\begin{tabular}{|l|l|l|l|l|l|l|}
\hline Nb & \multirow{2}{*}{ Potensi } & \multicolumn{1}{|c|}{ Satuan } & \multicolumn{4}{|c|}{ Tahun } \\
\cline { 4 - 7 } & & & 2012 & 2013 & 2014 & 2015 \\
\hline 1 & $\begin{array}{l}\text { Jumlah } \\
\text { Unit Usaha }\end{array}$ & Unit & 17 & 17 & 17 & 17 \\
\hline 2 & Investasi & IDR. Miliar & 2691 & 2801 & 2960 & 3256 \\
\hline 3 & $\begin{array}{l}\text { Tenaga } \\
\text { Kerja }\end{array}$ & Orang & 212 & 195 & 179 & 212 \\
\hline 4 & $\begin{array}{l}\text { Omset per } \\
\text { Tahun }\end{array}$ & IDR.Miliar & 7358 & 6478 & 7776 & 7776 \\
\hline
\end{tabular}

Tabel 1. Kondisi Industri Kampung Boneka Sukamulya

Berdasarkan catatan website sentra industri Bandung, di Kampung Boneka Sukamulya ini tercatat 17 pengrajin dengan 212 pekerja serta kapasitas produksi pertahun mencapai hampir 800.000 buah boneka dengan nilai investasi setara IDR.2.691 milyar. Hal lain yang membuat industri ini menarik berada pada produknya. Kualitas produksi boneka di Kampung Boneka ini sudah mendunia, tidak hanya menerima pesanan dari dalam negeri saja, namun sudah bisa mengekspor ke negara seperti China, Arab Saudi, New Zealand, Jerman, Jepang Dan Thailand. Ekspor merupakan nilai tambah bagi industri (Yudi Fernando et al. (2017))

2. Apakah masalah yang dihadapi Industri Kampung Boneka Sukamulya,

Boneka Sukamulya yang mengalami penurunan jumlah pengusaha aktif pada tahun 2014 - 2017. Jumlah pengusaha turun dari 10 pengusaha menjadi menjadi 4 pengusaha aktif. Penurunan jumlah pengusaha Sentra Boneka Sukamulya yang drastis ini dikarenakan menghadapi persaingan Masyarakat Ekonomi ASEAN pada tahun 2015. Masyarakat Ekonomi ASEAN turut mempengaruhi industri kreatif dan UKM (Ismail T. (2016), Ginting G.(2015), Mustofa et al. (2017), Sudayanto et al (2011), Dwi Budi Santosa (2018)

Sentra Boneka Sukamulya selain itu masalah dalam memasarkan para pengusaha Sentra Boneka Sukamulya masih mengandalkan pemasaran dari mulut ke mulut tanpa adanya upaya Dinas Perdagangan dan Perindustrian Kota Bandung mengadakan bazar untuk meningkatkan jumlah Produksi selain itu tidak adanya bantuan berupa modal untuk membantu pengusaha Sentra Boneka Sukamulya sehingga jumlah pengusaha mengalami penurunan dari tahun 2012-2014 yang berjumlah 2 pengusaha Boneka Sukamulya. Bantuan tidak berupa modal uang masih merupakan kebutuhan 
bagi industri boneka. Hal ini mengindikasikan bahwa pemerintah belum berpihak kepada pengusaha kecil (Phil 2011), menurut Porter (1980) industri boneka juga belum masuk dalam salah satu strategi keunggulan kompetitif yaitu fokus pada efisiensi biaya. Selain itu target pasar belum dilakukan oleh pengusaha, misalnya untuk remaja dan menguatkan positioning sebagai produk unggulan Kota Bandung (Cecep (2018), Hedrawan (2018))

Standar Nasional Indonesia (SNI) mewajibkan membayar setiap 6 bulan sebesar IDR 5 juta , dan harus diperpanjang, yang ditetapkan internal Bidang Sumber Daya dan Investasi Industri kepada setiap Sentra Boneka Sukamulya. Hal ini mengakibatkan semakin terpuruknya pengusaha Sentra Boneka Sukamulya karena biaya untuk mengikuti program tersebut cukup mahal. Hal ini bertentangan dengan model keunggulan bersaing Cravens (1999) yang mengharuskan adanya sumberdaya yang superior dan efisien sebagai sumber-sumber unggulannya.

Selain itu masih terkendala oleh masalah yang belum ada solusinya dari tahun 2012 dimana bahan baku yang mahal. Hal ini menurunnya jumlah produksi boneka. Hal ini mengakibatkan jumlah pengangguran semakin banyak dan komunikasi antara sesama pengusaha Sentra Boneka Sukamulya yang masih kurang. Kurang kerja sama dalam menentukan harga produk boneka mengakibatkan persaingan yang tidak sehat antar pengusaha. Selain itu masalah pemasaran yang masih mengandalkan pemasaran dari mulut kemulut. Keunggulan bersaing yang melibatkan Six P's, yaitu people (orang), policies (kebijakan), processes (proses), products (produk), practices (praktik) dan performance (kinerja) belum terjadi. Menurut Phil

\begin{tabular}{|c|c|c|}
\hline & Bermanfaat & membahayakan \\
\hline 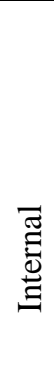 & $\begin{array}{l}\text { Strength } \\
\text { - Merupakan salah satu dari tujuh sentra } \\
\text { industri bandung } \\
\text { - Harga yang murah, mulai dari IDR. } \\
\text { 14.000,00 } \\
\text { - Terdapat empat jenis boneka dan satu jenis } \\
\text { matras } \\
\text { - Produk telah menjajah pasar internasional } \\
\text { - Produksi dilakukan masyarkat sekitar }\end{array}$ & $\begin{array}{l}\text { Weakness } \\
\text { - } \quad \text { Masih menggunakan teknik produksi yang } \\
\text { - } \\
\text { sederhana } \\
\text { Alat produksi yang masih sederhana dan } \\
\text { - } \quad \begin{array}{l}\text { Kurangnya kemampuan entreprenurial atau } \\
\text { berbisnis jangka panjang dari para pemilik } \\
\text { unit usaha }\end{array}\end{array}$ \\
\hline
\end{tabular}

(2011:103), keunggulan harus dipandang secara terintegrasi dan interaktif, adanya perbaikan berkelanjutan, dan hasil akhir yang dicapai adalah keunggulan kinerja.

3. Apakah keunggulan bersaing yang dapat diterapkan Industri Kampung Boneka Sukamulya dalam menghadapi permasalahan yang ada.

Hal ini karena Program Standar Nasional Indonesia (SNI) Dinas Perdagangan dan Perindustrian Kota Bandung Program Standar Nasional Indonesia (SNI) untuk Sentra Boneka Sukamulya hanya Sosialisasi untuk mengikuti program dengan syarat mempunyai Surat Izin Usaha Perdagangan dan membayar lima juta per enam bulan yang ditetapkan internal Bidang Sumber Daya dan Investasi Industri setelah itu akan diberikan label Standar Nasional Indonesia (SNI) dalam penetapan lima juta per enam bulan Dinas Perdagangan dan Perindustrian Kota Bandung ditetapkan Badan Standardisasi Nasional (BSN) sebagai lembaga pemerintah yang bertugas dalam pengembangan kegiatan standardisasi di Indonesia. Terhitung sejak Oktober 2013 lalu, di Indonesia, melalui Peraturan Menteri Perindustrian No.24/MInd/PER/4/2013 dengan revisi melalui Peraturan Menteri No.55/M- IND/PER/11/2013.

Dinas Perdagangan dan Perindustrian Kota Bandung hanya memberikan sosialisasi pentingnya mengikuti program tersebut tanpa adanya bantuan berupa modal yang di salurkan oleh Dinas Perdagangan dan Perindustrian Kota Bandung kepada pengrajin boneka karena tanpa memiliki Standar Nasional Indonesia (SNI) barang tidak bisa dijual di pasar nasional maupun global.

\section{Penelitian ini menggunakan metode analisis SWOT, dimana melalui metode ini kita dapat melihat keunggulan dan kekurangan Kampung Boneka Sukamulya.}




\begin{tabular}{|c|c|c|}
\hline 胥 & $\begin{array}{l}\text { Opportunity } \\
\text { - Kapasitas produksi per tahunnya sebanyak } \\
768.940 \text { unit dengan nilai investasi Rp. } \\
\text { 2,691 miliar } \\
\text { - Adanya teknologi dan perusahan IT Start- } \\
\text { Up Incubator yang bisa bekerja sama untuk } \\
\text { memasarkan produk langsung tanpa } \\
\text { melewati penggabah. Sehingga memiliki } \\
\text { laba yang lebih besar contoh } \\
\text { perusahaannya adalah KUDO.ID }\end{array}$ & 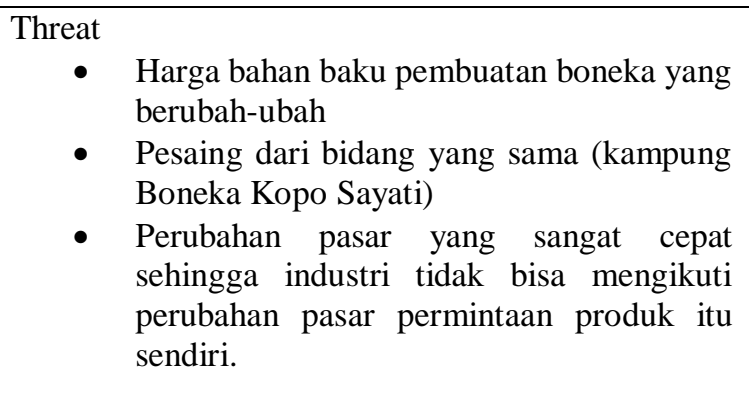 \\
\hline
\end{tabular}

Berdasarkan tabel analisis SWOT diatas jika dilihat dari bidang internal sendiri (Strength dan Weakness) Kampung Boneka Sukamulya memiliki keunggulan lebih pada bidang kekuatan, dilihat dari penetapan sebagai satu dari tujuh Sentra industri Bandung, harga yang terjangkau, produk yang berbagai jenis, serta produksi yang dilakukan oleh masyarakat sekitar. Hal ini sesuai dari salah satu indikator Cravens (1999) dalam modelnya yaitu keunggulan berupa sumberdaya yang murah (keunggulan positioning) dan Kepuasan, kesetiaan dan pangsa pasar (hasil kerja).

Dalam sisi Kelemahan, Kampung Boneka Sukamulya sendiri masih berpatokan pada cara pembuatan yang sederhana serta pada umumnya masih menggunakan tenaga manusia dengan kata lain, produksi boneka Kampung Boneka Sukamulya masih belum menggunakan alat moderen seperti pada pabrik modern saat ini. Dalam model Cravens (1999) belum muncul sumberdaya yang superior

Bidang eksternal menunjukan Kampung Boneka Sukamulya sendiri memiliki ancaman yang harus diantispasi mulai dari pesaing yang merupakan industri produksi boneka yang masih berada di satu daerah serta fluktuasi harga bahan baku pembuatan boneka itu sendiri. Phil (2011:103) keunggulan bagi suatu organisasi adalah tentang membedakan dirinya dengan the Six P's, yaitu people (orang), policies (kebijakan), processes (proses), products (produk), practices (praktik) dan performance (kinerja). Kampung Boneka Sukamulya masih kesulitan dalam kebijakan dan kinerjaNamun, Kampung Boneka Sukamulya sendiri memiliki potensi investasi yang besar dari kapasitas produksi yang sangat besar. Sehingga mampu menjadi daya tarik investor yang ingin mendapakan keuntungan dari investasi pada bidang produksi kriya ini.

\section{Strategi Strength-Opportunity (SO)}

1. Kampung Boneka Sukamulya memiliki peluang yang sangat besar untuk membuka peluang-peluang baru atau pasar-pasar baru di daerah lain dengan modal yang sangat efisien karena dibantu oleh perkembangan aplikasi teknologi. Inovasi yang ramah lingkungan ini (green innovation) akan meningkatkan keunggulan bersaing industri (Ardyan et al., 2017)

2. Varian produk baru yang bisa bersaing di pasar yang baru, Mengadakan penyuluhan dan pelatihan serta pendampingan terhadap industri kreatif ini karena adanya Badan Ekonomi Kreatif yang dibentuk Presiden Jokowi sehingga industri kreatif kriya ini bisa memiliki keberlangsungan yang cukup panjang dengan tenaga kerja yang professional nantinya.

3. Kampung Boneka Sukamulya memiliki harga yang relatif murah dari para pesaing dalam membuat unit produksi sehingga dapat memiliki kapabilitias untuk menjadi sentra industri yang bersifat "Top of Mind”. Sustainable competitive advantage akan meningkatkan kinerja pemasaran (Ardyan et al., 2017)

Strategi Strengh-Threat (ST)

1. Kampung boneka sukamulya dapat mempertahankan kualitas produk dengan membuat sistem quality control yang di standarisasi bersama dalam Sentra Industri Kampung Boneka Sukamulya agar terjadi kestabilan harga. (Cecep et al (2018))

2. Pemesanan bahan baku dengan bekerjasama antar para unit di Sukamulya yang nantinya bisa mendapatkan potongan harga dengan membuat perjanjian bersama dengan penyedia bahan baku atau yang disebut dengan nota kerjasama. Dengan cara ini dapat dipastikan bahwa bahan baku yang dibeli akan terjamin kualitas dan potongan harganya.

3. Memiliki channel yang sudah sampai pasar international, para pemilik sentra boneka tidak hanya memasok barang-barang yang diinginkan oleh konsumen international dan domestic namun juga mempertanyakan 
mengenai trend-trend yang sedang berlangsung saat ini agar tidak ketinggalan dengan perubahan permintaan konsumen yang sangat cepat jenuh dan berubah terhadap suatu produk.

Strategi Weakness-Opportunity (WO) ,

1. Kampung Boneka Sukamulya dapat memperkenalkan teknologi dengan penyuluhan-penyuluhan dari pemerintah khususnya dari Jawa Barat.

2. Melakukan event-event seperti Seminar UMKM atau Inkubasi UMKM dengan Informasi Teknologi Start-Up untuk memperkenalkan produk supaya dapat cepat terjual dan meningkatkan kapabilitias penjualan dari para pelaku sentra itu sendiri atau unit usaha itu sendiri.

Strategi Weakness-Threat (WT)

1. Kampung Boneka Sukamulya dapat membuat standar operational procedure yang jelas dan mudah dipahami oleh para pekerja, jika rumit dibuat pelatihan berjangka yang juga dimentori oleh Badan Ekonomi Kreatif.

2. Memperkenalkan kepada Sentra Industri Boneka mengenai penggunaan mesin atau aplikasi yang bisa membantu produksi dan pemasaran. Ketiga, Menanamkan semangat untuk kerjasama meskipun adanya persaingan, dimana adanya komunikasi antar sentra industri untuk menjaga kestabilan harga terlepas dari kompetisi yang ada agar tidak mengurangi nilai atau brand dari masing masing sentra.

\section{Kesimpulan}

1. Dalam rangka meningkatkan daya saing baik disektor usaha mikro, kecil dan menengah (UMKM), perlu adanya penerapan konsep keunggulan kompetitif. Ada jutaan pesaing yang akan menjadi ancaman nyata yang mampu mematikan usaha. Dampaknya adalah pertumbuhan perekonomian yang berakar pada kebertahanan usaha. Peran akademisi, praktisi, Lembaga riset serta pemerintah untuk menghasilkan kajian-kajian terkait keunggulan kompetitif suatu usaha. Keterkaitan antara pihak akademisi, praktisi, lembaga riset serta pemerintah dengan pelaku usaha, perusahaan, industri, serta pelaku usaha adalah pengembangan konsep, gagasan dan ide tentang competitive advantage.
2. Kampung Boneka Sukamulya memiliki potensi besar dalam perkembangan industri kreatif khususnya subsektor kriya. Potensi ini dapat memberikan andil besar dalam pertumbuhan ekonomi kreatif dan penyerapan tenaga kerja. Kampung Boneka Sukamulya sendiri masih memiliki kendala yang harus dihadapi berupa bahan baku dan pesaing.

3. Industri kriya sangat bergantung pada bahan baku yang tersedia, begitu pun dengan Kampung Boneka Sukamulya, jika terjadi perubahan pasokan bahan baku atau perubahan pada harga bahan baku akan berdampak pada beberapa aspek penting termasuk kapasitas produksi dan harga.

4. Perubahan kuantitas tenaga kerja pada kampung boneka sukamulya dapat diatasi melalui pelatihan terhadap karyawan sehingga mampu menjadi sumber daya mauniasia yang terlatih, profesional dan efisien.

\section{Rekomendasi}

Berdasarkan hasil analisis dan diskusi yang telah dilakukan oleh peneliti, peneliti memberikan beberapa saran yang dapat diterapkan agar sentra industri kampung boneka Sukamulya dapat berkembang dimasa yang akan datang.

(1) Memberikan pelatihan terhadap karyawan atau sumber tenaga kerja manusia agar lebih terampil dalam proses produksi selain itu pengenalan terhadap mesin dan aplikasi yang dapat menunjang produksi dan pemasaran produk.

(2) mempertahankan kualitas produk dan harga agar dapat mempertahankan konsumen dan pasar.

\section{Daftar Pustaka}

Ardyan E., Nurtantiono A., Istiyanto B., Rahmawan G. (2017). Green innovation capability as driver of sustainable competitive advantages and smes marketing performance. International Journal of Civil Engineering and Technology

Banaeianjahromi., $\mathrm{N} \quad \& \quad$ Smolander., K. (2016). "What do we know about the role of enterprise architecture in enterprise integration? A systematic mapping study", Journal of Enterprise Information Management, Vol. 29 Iss 1 pp. 140 - 164

Barney., J. B. (1986). Organizational culture: can it be a source of sustained competitive advantage?. Academy o/Monogemen/Review. 1986, Vol. 11. No. 3. 656-665. 
Barney., J. B. (1988). Returns To Bidding Firms In Mergers And Acquisitions: Reconsidering The Relatedness Hypothesis. Strategic Management Journal, Vol. 9, 71-78 (1988).

Barney., J. B. (1991). Firm Resources and Sustained Competitive Advantage. Journal of Management 1991 17: 99

Barney., J. B. (1996). Information Technology and Sustained Competitive Advantage: A Resource-Based Analysis. Executive Overview. Page 487

Barney., J. B. (2001). The resource-based view of the firm: Ten years after 1991. Journal of Management 27 (2001) 625-641

Barney., J. B. \& Clark., Delwyn N. (2001). Resource-Based Theory: Creating and Sustaining Competitive Advantage. Oxford University Press Inc., New York.

Booyens, I. (2012). Creative industries, inequality and social development: Developments, impacts and challenges in Cape Town. Urban Forum, 23, 43 - 60.

Budiarto D.S., Prabowo M.A., Herawan T. (2017). An integrated information system to support supply chain management \& Performance in SMEs. Journal of Industrial Engineering and Management.

Cecep Safa'atul et al (2018) Analysis of marketing strategies and competitive advantages of two producers special foods in Garut, International Journal of Trade and Global Markets, Volume 11, Issue 1-2

Cravens, D.W. (1999), Strategic Marketing, 6th ed., Irwin/McGraw-Hill, Homewood, IL.

Dimas Hendrawan, Dian Ari Nugroho (2018) Influence of personality on impulsive buying behaviour among Indonesian young consumers, International Journal of Trade and Global Markets, Volume 11, Issue 1-2

Dong, L., \& Haruna, M. (2012). The practice of urban renewal based on creative industry: Experience from the Huangjueping creative industries in Chongqing China. Journal of Sustainable Development, 5, $101-110$.

Dwi Budi Santosa (2018) Does export promotion policy benefit for ASEAN economic development? International Journal of Trade and Global Markets, Volume 11, Issue 1-2

Ginting G. (2015). Network resources as a key determinant of small medium enterprises/SMES export performance (Case: Creative industry in Indonesia).
International Journal of Applied Business and Economic Research

http://panduanwisata.id

Ismail T. (2016). Culture control, capability and performance: Evidence from creative industries in Indonesia. Asian Review of Accounting

Juniarti (2017) The negative impact of family ownership structure on firm value in the context of Indonesia, International Journal of Business and Globalisation, Volume 11, Issue 1

Kahkonen, T., \& Smolander, K. (2013). ERP Integration: A Systematic Mapping Study. Proceedings of the 15th International Conference on Enterprise Information Systems ISBN 978-989-8565-59-4, Angers, France, 23-35.

Kahkonen, T., \& Smolander, K. (2013). ERP Integration: A Systematic Mapping Study. Proceedings of the 15th International Conference on Enterprise Information Systems ISBN 978-989-8565-59-4, Angers, France, 23-35.

Kitchenham, B. (2004). Procedures for performing systematic reviews. Keele University, Keele.

Kitchenham, B. (2007). Guidelines for performing Systematic Literature Reviews in Software Engineering. EBSE Technical Report, School of Computer Science and Mathematics, Keele University, UK, 1-57.

Laporan Penyusunan PDRB Ekonomi Kreatif5 Provinsi 87 2010-2016 Menurut Lapangan Usaha

Mustofa M.S., Ngabiyanto, Santoso A.B. 2017. Innovation and social capital in the development of embroidery industry in Nalum sari sub district of Jepara regency, central Java (a study in Nalum sari and Daren Villages). International Journal of Applied Business and Economic Research

Napitupulu T.A., Ika L.R. (2013). B2B website's model of satisfaction and benefit: A case of $S M E$ in Indonesia. International Business Management

Petersen, K. F. (2008). Systematic mapping studies in software engineering. 12th International Conference on Evaluation and Assessment in software engineering, p.1.

Porter, M. E. (1980). Competitive strategy: techniques for analyzing industries and competitors: with a new introduction1 Michael E. Porter. New York, United States of America: The Free Press; First Free Press Edition 1980; ISBN 0-68484148-7. 
Roostika R., Wahyuningsih T., Haryono S. (2015). The impacts of external competitiveness factors in the handicrafts industry. Polish Journal of Management Studies

Rufaidah P. (2016). Dynamic capability in branding strategy development. International Journal of Economics and Management

Rukmawati, R. (2009). Industri Kreatif di Indonesia. Jakarta: MPKP FEUI.

Samsir, Nursanti A., Zulfadil. (2017). The effect of product innovation as mediation in relationship between knowledge management to competitive advantage (Case study in SME of typical food products of Riau Indonesia). International Journal of Economic Research.

Sudaryanto, Ragimun. 2011. Strategi Pemberdayaan UMKM Menghadapi

Pasar. Bebas Asean. Yogyakarta: Kedaulatan Rakyat.

Sulistyo H., Siyamtinah. (2016). Innovation capability of SMEs through entrepreneurship, marketing capability, relational capital and empowerment. Asia Pacific Management Review
Susanti A.A., Arief M. (2015). The effect of dynamic capability for the formation of competitive advantage to achieve firm's performance (Empirical study on Indonesian credit cooperatives). Advanced Science Letters

Tjahjaningsih E., Rozak H.A., Handayani D., Utomo A.P. (2016). Development and empowerment of Semarang batik craftsmen based on assistance strategy of fractal batik in the effort to build sustainable competitive advantage. International Journal of Applied Business and Economic Research

Widodo, Shahab M.A. (2015). The model of human capital and knowledge sharing towards sustainable competitive advantages. Problems and Perspectives in Management

Yudi Fernando, Agustina Fitrianingrum, Christopher Richardson (2017) Organisational determinants of export performance: evidence from exporting firms in Batam, Indonesia, International Journal of Business Excellence Volume 11, Issue 1 